\title{
Whale-watching: Sustainable tourism and ecological management
}

Edited by James Higham, Lars Bejder, Rob Williams. Cambridge University Press < $<w w . c a m b r i d g e$. org>, 2014, ix + 378 pp. (figures, tables, index), Price AU\$127 Hbk. ISBN: 978-0-521-19597-3.

Solid, dense, and rich in information, this compilation makes a valuable contribution to the global literature on whale-watching. There is a degree of overlap amongst its 25 chapters, and its themes and geographic coverage reflect the origins and interests of its 48 contributors. Review chapters include relevant literature worldwide, but the coverage of case study chapters is less comprehensive. In addition, in order to squeeze so many words into 387 pages, the publishers have picked a font that almost qualifies it as a microfiche, definitely a false economy.

Although the subtitle of the book is Sustainable Tourism and Ecological Management, the dominant theme is the comparison of whale-watching with whaling. Three comparative subthemes reoccur across a number of chapters: history, ecological impacts, and economic returns. In addition, several authors consider to what degree whaling and whale-watching can coexist at various different geographical scales. For migratory species, whaling in one place will affect whale-watching in others. For individual nations, whaling reduces inbound tourism. For the whale-watching industry, seeing individual whales being harpooned by whalers is traumatic for the tourists and bad for the tour businesses.

These conflicts and concerns lead to a number of research questions addressed by several of these authors but not fully answered. For example, where nations which engage in whaling also offer whalewatching tours, should whale conservation NGOs encourage tourists to take those tours so as to demonstrate the economic value of whale-watching? Or, should they encourage tourists to boycott those countries completely, to demonstrate the economic costs of whaling? Secondly, should whalers be able to gain exclusive access to particular areas, keeping whale-watchers out? Apparently, there have been cases where whalers have attempted to sue whale-watching businesses, supposedly for interfering with their operations. This is a more complicated legal question than its terrestrial analogues because access to territorial waters of individual nations is commonly controlled at wholeof-government level, not by a single portfolio such as a parks or forestry agency. The third question is the degree to which social attitudes towards whaling and whale-watching cross over between different cetacean species. Are tourists happy to swim with dolphins, for example, whilst simultaneously knowing that minke whales are being hunted? The fourth question relates to whaling by Indigenous for First Nations peoples. How is tourism based on bowhead, beluga or narwhal in the Canadian Arctic, for example, affected by Indigenous hunting of whales; and does it make any difference whether the whales are hunted for local human consumption, to feed dogs, to sell in tourist restaurants, or for sale of body parts such as narwhal tusks (Buckley, 2005)?

For those cetacean species and subpopulations that are reasonably well protected and not subject to whaling, there are also numerous research questions related to anthropogenic impacts both from whale-watching tourism and from other industries. Many oceanic species, for example, are affected by noise impacts from undersea petroleum exploration. Estuarine and riverine subpopulations suffer from pollution and propeller strike, e.g. in the St Lawrence River in Canada, the Yangtze in China, and the 
Amazon River in Brazil. There are also subpopulations that experience particular impacts from tourism. Sperm whales in Kaikoura, New Zealand, for example, shorten their surface breathing periods when under observation from helicopters. Dolphins at Tangalooma and Shark Bay in Australia are routinely fed by tourists.

This volume does not answer any of those questions comprehensively. It does, however, raise these issues in the individual chapters and case studies, in sufficient detail that the reader is intrigued to know more.

\section{Reference}

Buckley, R. (2005). In search of the narwhal: Ethical dilemmas in ecotourism. Journal of Ecotourism, 4(2), 129-134.

Ralf Buckley International Chair in Ecotourism Research, Griffith University, Gold Coast, Queensland 4222, Australia Tel.: +61 (0)7 5552 8675; fax: +61 (0)7 55528895 .

E-mail address: r.buckley@griffith.edu.au 